\section{OPEN ACCESS}

Edited and reviewed by: Jinhui Wang.

South China Normal University, China

\section{*Correspondence:}

Ti-Fei Yuan

ytf0707@126.com

Yulian Zhu

zyljully@163.com

tThese authors have contributed equally to this work and share first authorship

Specialty section

This article was submitted to Neural Technology, a section of the journal Frontiers in Neuroscience

Received: 30 March 2021 Accepted: 06 April 2021

Published: 05 May 2021

Citation:

Yu F, Tang X, Hu R, Liang S, Wang W.

Tian S, Wu Y, Yuan T-F and Zhu Y (2021) Corrigendum: The After-Effect

of Accelerated Intermittent Theta Burst Stimulation at Different Session Intervals. Front. Neurosci. 15:687972. doi: 10.3389/fnins.2021.687972

\title{
Corrigendum: The After-Effect of Accelerated Intermittent Theta Burst Stimulation at Different Session Intervals
}

\begin{abstract}
Fengyun $\mathrm{Yu}^{1,2 \dagger}$, Xinwei Tang ${ }^{1 \dagger}$, Ruiping $\mathrm{Hu}^{1+}$, Sijie Liang ${ }^{2}$, Weining Wang ${ }^{2}$, Shan Tian ${ }^{1}$, Yi Wu ${ }^{1}$, Ti-Fei Yuan ${ }^{3,4 *}$ and Yulian Zhu ${ }^{1 *}$

${ }^{1}$ Department of Rehabilitation Medicine, Huashan Hospital, Fudan University, Shanghai, China, ${ }^{2}$ School of Kinesiology, Shanghai University of Sport, Shanghai, China, ${ }^{3}$ Shanghai Key Laboratory of Psychotic Disorders, Shanghai Mental Health Center, Shanghai Jiao Tong University School of Medicine, Shanghai, China, ${ }^{4}$ Co-innovation Center of Neuroregeneration, Nantong University, Nantong, China
\end{abstract}

Keywords: theta burst stimulation, accelerated, motor cortex, cortical plasticity, stimulation interval

\section{A Corrigendum on}

The After-Effect of Accelerated Intermittent Theta Burst Stimulation at Different Session Intervals

by Yu, F., Tang, X., Hu, R., Liang, S., Wang, W., Tian, S., et al. (2020). Front. Neurosci. 14:576. doi: 10.3389/fnins.2020.00576

In the original article, there was a mistake in the legend for Figure 5(C) and Figure 6(D) as published. It should be "iTBS $600 \times 3^{*} 30$," but it was written incorrectly to "iTBS $\times 3^{*} 10$." The correct legend appears below.

Figure 5. Individual response to iTBS after 1800 pulses stimulation in three different intervals. (A) iTBS1800 (B) iTBS600 × $3^{*} 10$ (C) iTBS600 $\times 3^{*} 30$.

Figure 6. The percentage of subjects that responded to different iTBS conditions. (A) one blocks of iTBS (B) iTBS1800 (C) iTBS600 × 3*10 (D) iTBS600 × $3^{*} 30$.

In the original article, there was a mistake in Table 2 as published. The corrected Table 2 appears below. The SI $1 \mathrm{mv}$ data for iTBS600×3*10 was incorrectly filled in as 198.2.

The authors apologize for this error and state that this does not change the scientific conclusions of the article in any way. The original article has been updated.

Copyright () $2021 \mathrm{Yu}$, Tang, Hu, Liang, Wang, Tian, Wu, Yuan and Zhu. This is an open-access article distributed under the terms of the Creative Commons Attribution License (CC BY). The use, distribution or reproduction in other forums is permitted, provided the original author(s) and the copyright owner(s) are credited and that the original publication in this journal is cited, in accordance with accepted academic practice. No use, distribution or reproduction is permitted which does not comply with these terms. 
TABLE 2 | Subjects' baseline RMT, MEP amplitude, $\mathrm{SI}_{1 \mathrm{mv}}$, and LICI when started three different iTBS conditions.

\begin{tabular}{|c|c|c|c|c|c|}
\hline & $\begin{array}{l}\text { iTBS1800 } \\
(N=16)\end{array}$ & $\begin{array}{l}\text { iTBS600 } \times 3^{*} 10 \\
(N=16)\end{array}$ & $\begin{array}{l}\text { iTBS600 } \times 3^{*} 30 \\
(N=16)\end{array}$ & $F$ & $P$ \\
\hline $\begin{array}{l}\text { RMT } \\
\text { (\%MSO) }\end{array}$ & $\begin{array}{l}39.69 \pm \\
15.99\end{array}$ & $40.31 \pm 14.70$ & $40.38 \pm 14.45$ & 0.010 & 0.990 \\
\hline $\begin{array}{l}\text { MEP } \\
(\mathrm{mV})\end{array}$ & $1.03 \pm 0.23$ & $1.22 \pm 0.43$ & $1.14 \pm 0.35$ & 1.272 & 0.290 \\
\hline $\begin{array}{l}\mathrm{Sl}_{1 \mathrm{mv}} \\
(\% \mathrm{MSO})\end{array}$ & $50.8 \pm 20.05$ & $51.88 \pm 19.82$ & $52.25 \pm 17.19$ & 0.025 & 0.975 \\
\hline $\mathrm{LICl}$ & $0.37 \pm 0.46$ & $0.22 \pm 0.35$ & $0.24 \pm 0.41$ & 0.662 & 0.521 \\
\hline
\end{tabular}

